\title{
Fixation of $\mathrm{N}_{2}$ by Bacteroids from Stem Nodules of Sesbania rostrata
}

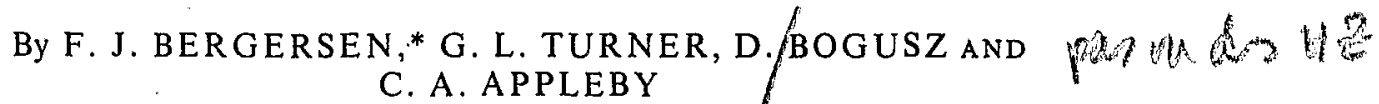 \\ CSIRO Division of Plant Industry, GPO Box 1600, Canberra, ACT 2601, Australia
}

(Received 21 October 1987; revised 16 March 1988)

Bacteroids, prepared from stem nodules of Sesbania rostrata inoculated with Rhizobium sp. strain. ORS571, in steady-state reactions in which $\mathrm{O}_{2}$ was supplied in solution with soybean leghaemoglobin or mammalian myoglobin as $\mathrm{O}_{2}$ carriers, and with succinate as exogenous substrate, fixed $\mathrm{N}_{2}$ to $\mathrm{NH}_{3}$ with highest rates at $10 \mathrm{nM}$ free $\mathrm{O}_{2}$, where $\mathrm{O}_{2}$ uptake was approximately half-maximal. Higher concentrations ( $>100 \mathrm{nM}$ ) of free $\mathrm{O}_{2}$, shown previously to be required for optimum nitrogenase activity in $\mathrm{O}_{2}$-trained ORS571 grown in continuous culture, inhibited $\mathrm{N}_{2}$ fixation by stem nodule bacteroids.

\section{INTRODUCTION}

Bacteroids from stem nodules of Sesbania rostrata increased their $\mathrm{O}_{2}$ consumption and nitrogenase activity at increasing concentrations of free dissolved $\mathrm{O}_{2}$ up to $15 \mathrm{nM}$. At these very low concentrations, sesbania stem nodule leghaemoglobin was better than soybean leghaemoglobin in the facilitation of $\mathrm{O}_{2}$ flux (Bergersen et al., 1986). However, studies at higher concentrations of free $\mathrm{O}_{2}$ were prevented because of shortage of stem nodules at that time. The same bacteria grew and fixed $\mathrm{N}_{2}$ efficiently at $7-10 \mu \mathrm{M}$ dissolved $\mathrm{O}_{2}$ in continuous culture, but when grown at $<1 \mu \mathrm{M}-\mathrm{O}_{2}$, nitrogenase activity was impaired above $0.1 \mu \mathrm{M}-\mathrm{O}_{2}$ (Bergersen $e$ al al, 1986). Thus it would be of interest to establish the sensitivity to $\mathrm{O}_{2}$ of nitrogen fixation by the symbiotic forms of these bacteria. Trinchant \& Rigaud (1987) found, with a different experimental system, that stem nodule bacteroids with succinate increased their nitrogenase activity in the range $5-20 \mathrm{nM}-\mathrm{O}_{2}$; no decline in activity was recorded up to $50 \mathrm{nM}$. In this paper we report the steady-state relationship between rates of $\mathrm{O}_{2}$ consumption and $\mathrm{N}_{2}$ fixation by stem nodule bacteroids, in the range 6-1400 nM free dissolved $\mathrm{O}_{2}$, using soybean leghaemoglobin and mammalian myoglobin in the reaction solutions.

\section{METHODS}

Plants, growth and production of nodules. Stem nodules on Sesbania rostrata inoculated with Rhizobium sp. strain ORS571, were produced, and bacteroid suspensions prepared from them, as described by Bergersen et al. (1986).

Flow chamber methods. The apparatus consisted of a stirred reaction chamber, in which bacteroid suspensions were retained and supplied with a flow of solution containing dissolved air, soybean oxyleghaemoglobin or sperm whale oxymyoglobin and $10 \mathrm{~mm}$-succinate. The absorption spectrum of the effluent solution passing from the chamber through a spectrophotometer flow cell allowed monitoring of haemoglobin deoxygenation in the chamber and thus free $\mathrm{O}_{2}$ concentration and $\mathrm{O}_{2}$ consumption rates could be calculated. Except for measurement of $\mathrm{N}_{2}$ fixation, the apparatus, solutions, analytical methods and methods for recording data and calculation, were all as described previously (Bergersen et al., 1986).

Measurement of nitrogenase activity. Nitrogenase activity was assayed as the production of ammonia in solution (Bergersen \& Turner, 1967), rather than by reduction of $\mathrm{C}_{2} \mathrm{H}_{2}$ to $\mathrm{C}_{2} \mathrm{H}_{4}$ (Bergersen et al, 1986; Gebhardt et al., 1984; Trinchant \& Rigaud, 1987). In the apparatus used, experiments with bacteroids from other legumes, in which dissolved $\mathrm{C}_{2} \mathrm{H}_{2}$ was progressively replaced by dissolved $\mathrm{N}_{2}$ (and vice versa) as substrates for nitrogenase (F. J. Bergersen \& G. L. Turner, unpublished) showed no differences between rates of appearance of $\mathrm{C}_{2} \mathrm{H}_{4}$ from $\mathrm{C}_{2} \mathrm{H}_{2}$ and $\mathrm{NH}_{3}$ from $\mathrm{N}_{2}$. Rates of $\mathrm{N}_{2}$ fixation were calculated from the concentration of $\mathrm{NH}_{4}^{+}$in the effluent

$0001-4487$ (C) 1988 SGM

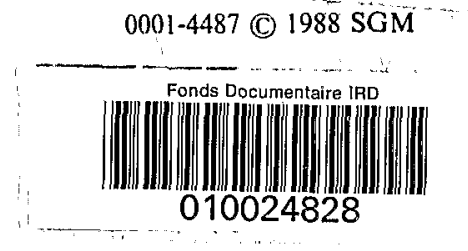

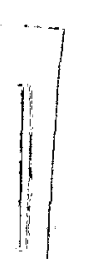



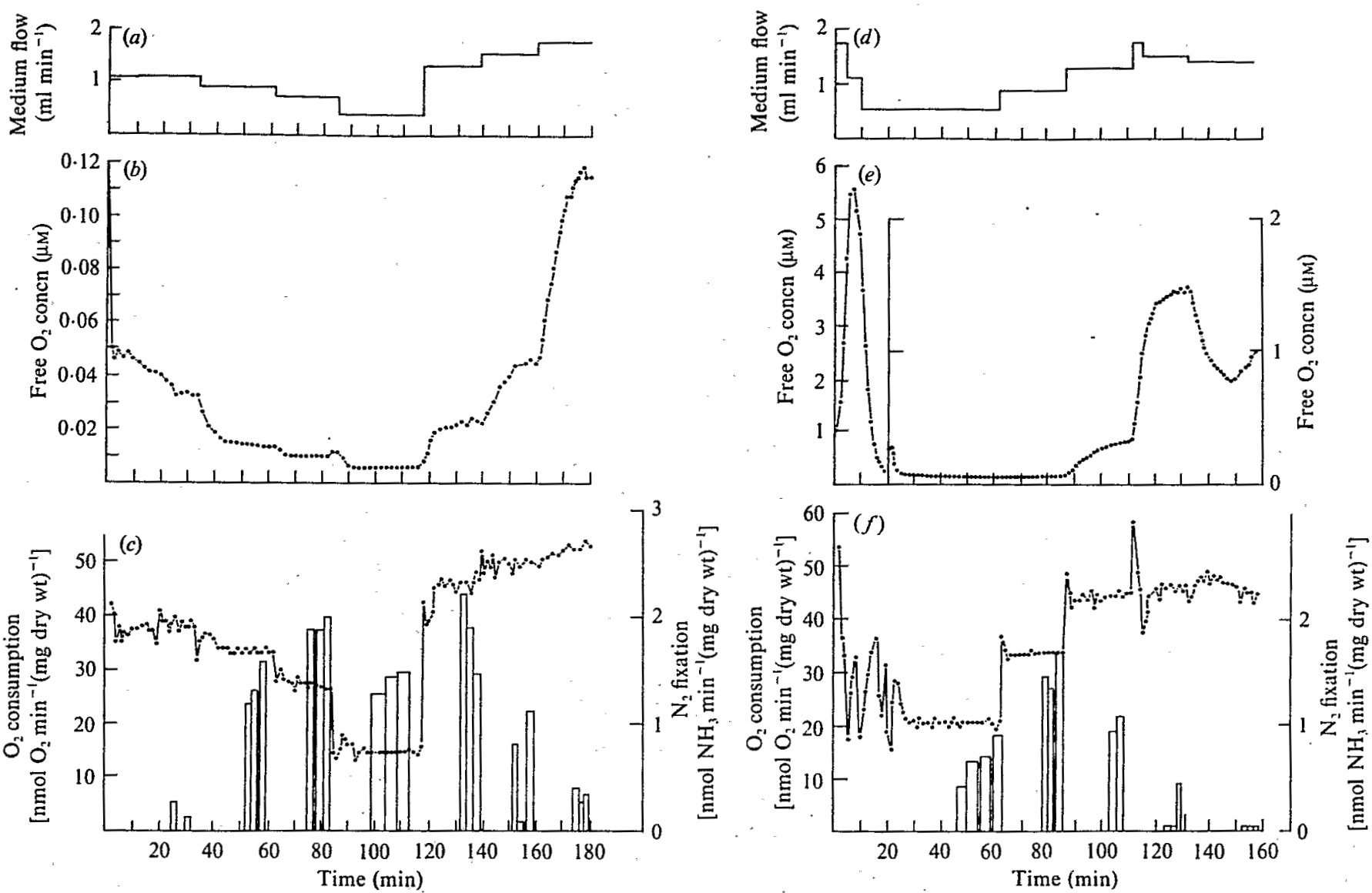

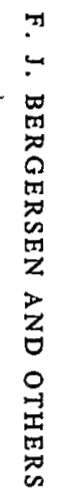

Fig. 1. Time-courses of flow chamber reactions with stem nodule bacteroids from Sesbania rostrata. The reaction solution, supplied at rates shown in (a), contained $103.4 \mu \mathrm{M}$-oxyleghaemoglobin (soybean), $10 \mathrm{mM}$-succinate, $250.4 \mu \mathrm{M}$ dissolved $\mathrm{O}_{2}$, in $25 \mathrm{mM}$-potassium phosphate buffer, $\mathrm{pH} 7.4$, with $2 \mathrm{~mm}$ - $\mathrm{MgSO}_{4}$. Concentrations of free dissolved $\mathrm{O}_{2}$, calculated from oxygenation of leghaemoglobin in the effluent solution are shown in $(b)$ and rates of $\mathrm{O}_{2}$ consumption $(\mathbf{O})$ and $\mathrm{N}_{2}$ fixation (bars) in $(c)$. The reaction solution, supplied at rates shown in $(d)$, was as above but with $96.2 \mu \mathrm{M}$ sperm whale oxymyoglobin and $244.5 \mu \mathrm{M}$ free dissolved $\mathrm{O}_{2}$. $\mathrm{O}_{2}$ concentrations and reaction rates are shown in $(e)$ and $(f)$ respectively. The $\mathrm{O}_{2}$ data are plotted at intervals of 1 min. $\mathrm{N}$, fixation rates are calculated from concentrations of $\mathrm{NH}_{+}^{+}$in $2.0 \mathrm{ml}$ samples of effluent solution and plotted as bars of width indicating the period of collection. The chamber contained 9-1 mg dry wt of bacteroids in the chamber for both reactions. 

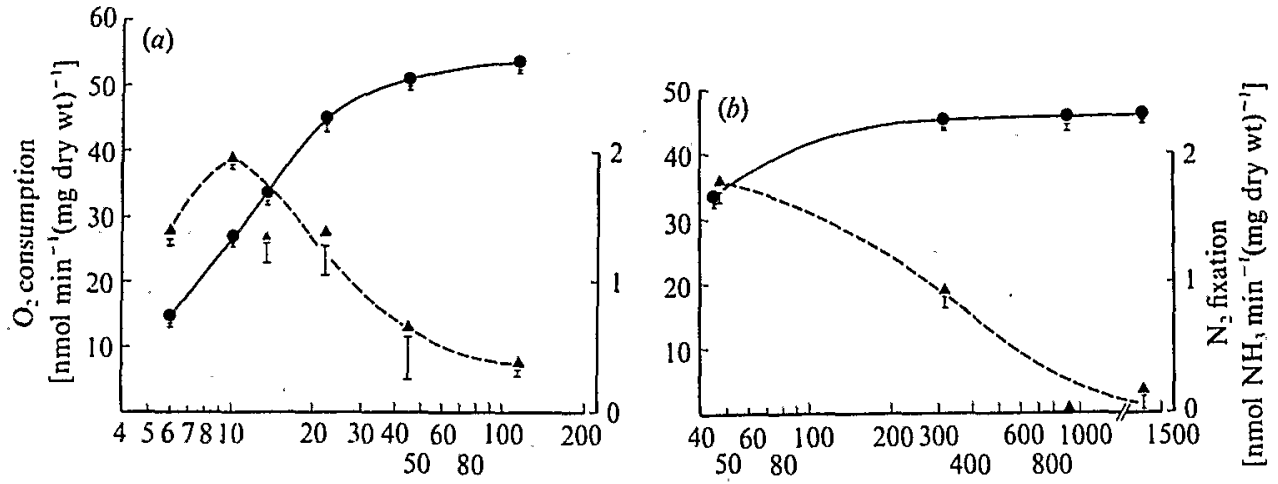

Free, dissolved $\mathrm{O}_{2}$ conc $(\mu \mathrm{M})$

Fig. 2. Steady-state rates of $\mathrm{O}_{2}$ consumption and $\mathrm{N}_{2}$ fixation in relation to concentration of free dissolved $\mathrm{O}_{2}$. Results from the experiments shown in Fig. $1 . \mathrm{O}_{2}$ consumption (C) and $\mathrm{N}_{2}$, fixation $(\boldsymbol{A})$ are shown with $(a)$ leghremoglobin and $(b)$ myoglobin. Vertical bars indicate SEM values of three to four rate measurements. SE values for $\mathrm{O}_{2}$ concentration during each rate measurement are smaller than the symbols.

solution and the medium flow rate. The concentration of $\mathrm{NH}_{4}^{+}$was measured in samples $(0.9 \mathrm{ml})$ of effluent solution, by the colorimetric method of Chaney and Marbach (Bergersen, 1980), using standards $(0.25-6 \mu \mathrm{g}$ $\mathrm{NH}_{\perp}^{+}-\mathrm{N}$ ) in $0.9 \mathrm{ml}$ of reaction solution.

Steady-state measurements of $\mathrm{O}_{2}$ consumption and $\mathrm{N}_{2}$ fixation. Steady rates of $\mathrm{O}_{2}$ supply were usually established for at least $20 \mathrm{~min}$ before collecting three or four samples $(2.0 \mathrm{ml}$, timed by stop-watch) of effluent solution for estimation of $\mathrm{NH}_{+}^{+}$. However, at the beginning of experiments more time was allowed for the establishment of the initial. steady state, before the first samples were collected.

\section{RESULTS AND DISCUSSION}

Data from representative experiments (Fig. 1) show most of the previously reported features of stem nodule bacteroids and of the same bacteria grown in continuous culture at low concentrations of dissolved $\mathrm{O}_{2}$ (Bergersen et al., 1986). However, in addition, the data include observations over a much greater range of concentration of free dissolved $\mathrm{O}_{2}$, include measurements made in the presence of oxymyoglobin instead of oxyleghaemoglobins, and present $\mathrm{N}_{2}$ fixation measurements (production of $\mathrm{NH}_{3}$ from $\mathrm{N}_{2}$ ) rather than $\mathrm{C}_{2} \mathrm{H}_{2}$ reduction for nitrogenase activity. The following findings have not previously been reported. (I) In each experiment there was an initial, of ten brief, exposure to concentrations of free $\mathrm{O}_{2}$ near or above $1 \mu \mathrm{M}$ and initial rates of $\mathrm{N}_{2}$ fixation were low. During and immediately following this period, $\mathrm{O}_{2}$ consumption rates were not closely related to the concentration of free $\mathrm{O}_{2} . \mathrm{N}_{2}$ fixation was restored after 30-60 min, provided that the $\mathrm{O}_{2}$ concentration was less than about $100 \mathrm{nM}$. These effects are seen particularly well in the oscillations in $\mathrm{O}_{2}$ consumption during the first $30 \mathrm{~min}$ (Fig. $1 c, f$ ) and in the increasing $\mathrm{N}_{2}$ fixation rates between 46 and 62 min (Fig. $1 f$ ). (II) In agreement with Trinchant \& Rigaud (1987), who used a non-steady-state experimental system, steady-state measurement showed that stem nodule bacteroids supplied with succinate have greatest nitrogenase activity near $10 \mathrm{nM}$ free dissolved $\mathrm{O}_{2}$, where steady-state $\mathrm{O}_{2}$ consumption rates are near half-maximal (Fig. 2). (III) Steady rates of $\mathrm{N}_{2}$ fixation were lower at $6 \mathrm{nM}$ free dissolved $\mathrm{O}_{2}$, where respiration was also much lower (Fig. 2). (IV) When steady-state concentrations of free dissolved $\mathrm{O}_{2}$ exceeded $20 \mathrm{nM}$ in the presence of oxyleghaemoglobin or $100 \mathrm{nM}$ with oxymyoglobin, $\mathrm{O}_{2}$ consumption rates approached maximum values and $\mathrm{N}_{2}$ fixation was inhibited (Fig. 2). In these conditions it seems to be likely that penetration of the bacteroids by $\mathrm{O}_{2}$ occurs, leading to inactivation of nitrogenase, perhaps by covalent modification of nitrogenase reductase, as described for photosynthetic diazotrophic bacteria (Ludden et al., 1984). This is supported by the comparatively rapid restoration of $\mathrm{N}_{2}$ fixation following a brief initial exposure to excess $\mathrm{O}_{2}$ (Fig. $1 f$ ), although the de novo synthesis of new nitrogenase cannot be excluded. (v) If there was a fixed relationship between concentrations of free dissolved $\mathrm{O}_{2}$, 
rates of $\mathrm{O}_{2}$ consumption and rates of $\mathrm{N}_{2}$ fixation, as suggested by Fig. 2, the imposition of a changed rate of $\mathrm{O}_{2}$ supply would cause a predictable change in concentration to a level appropriate for $\mathrm{O}_{2}$ consumption at that rate of supply. Fixation of $\mathrm{N}_{2}$ would also change accordingly. Generally, steady-state measurements conformed to the relationships shown in Fig. 2. However, as reported previously for the same bacteria from continuous culture grown at low concentrations of dissolved $\mathrm{O}_{2}$ (Bergersen et al., 1986), stem nodule bacteroids sometimes consumed $\mathrm{O}_{2}$ at widely different rates with little or no detectable change in prevailing concentrations of free $\mathrm{O}_{2}$. This is seen in Fig. $1 e, f$, where there was an increasing rate of $\mathrm{N}_{2}$ fixation between 45 and $62 \mathrm{~min}$, indicating that a steady state was not yet established, despite steady consumption of $\mathrm{O}_{2}$ and steady concentrations of free $\mathrm{O}_{2}$ since $30 \mathrm{~min}$. Following an increase in supply of $\mathrm{O}_{2}$ at $63 \mathrm{~min}$, a new and greater steady rate of $\mathrm{O}_{2}$ consumption was established within $3 \mathrm{~min} ; \mathrm{N}_{2}$ fixation was greater also but there was no discernible change in concentration of free dissolved $\mathrm{O}_{2}$. Thus, the relationships between respiration rate and concentration of free $\mathrm{O}_{2}$ shown in Fig. 2 are not invariate. The lack of a fixed relationship between $\mathrm{O}_{2}$ concentration and $\mathrm{O}_{2}$ consumption rates and the existence of time-dependent changes in rates during pre-steady-state adjustments in these bacteria, make extremely difficult the interpretation of short-term experiments in which $\mathrm{O}_{2}$ concentration is continually changing and which attempt to relate apparent differences in optimal $\mathrm{O}_{2}$ concentrations to utilization of different substrates (Trinchant \& Rigaud, 1987). (vI) Finally, it is clear that bacteroids from stem nodules of $S$. rostrata lack the $\mathrm{O}_{2}$-tolerant $\mathrm{N}_{2}$-fixing system present in continuous cultures grown at $7-10 \mu \mathrm{M}$ dissolved $\mathrm{O}_{2}$. It is therefore unlikely that the presence of apparently active photosynthetic tissue in the cortex of stem nodules (Dreyfus \& Dommergues, 1981) results in greater exposure of the symbiotic tissue to $\mathrm{O}_{2}$ than is the case in root nodules.

\section{REFERENCES}

BERGERSEN, F. J. (1980). Measurement of nitrogen fixation by direct means. In Methods of Evaluating Biological Nitrogen Fixation, p. 75. Edited by F. J. Bergersen. Chichester: John Wiley.

BERgERSEN, F. J. \& TURNER, G. L. (1967). Nitrogen fixation by the bacteroid fraction of breis of soybean root nodules. Biochimica et biophysica acta 141, 507515.

Bergersen, F. J., Turner, G. L., Bogusz, D., WU, Y.-Q. \& APplebY, C. A. (1986). Effects of $\mathrm{O}_{2}$ concentrations and various haemoglobins on respiration and nitrogenase activity of bacteroids from stem and root nodules of Sesbania rostrata and of the same bacteria from continuous culture. Journal of General Microbiology 132, 3325-3336.

DREYFus, B. L. \& DOMmergues, Y. R. (1981). Nitrogen-fixing nodules induced by Rhizobium on the stem of the tropical legume Sesbania rostrata. FEMS Microbiology Letters 10, 13-23.

Gebhardt, C., Turner, G. L., Gibson, A. H., Dreyfus, B. L. \& Bergersen, F. J. (1984). Nitrogen fixing growth in continuous culture of a strain of Rhizobium sp. isolated from stem nodules on Sesbania rostrata. Journal of General Microbiology 130 , 843-848.

LudDen, P. W., Murrell, M. P., Kanemoto, R., Dowling, T. E., SAARI, L. L. \& TRIPLeTT, E. (1984). Regulation of nitrogen fixation in photosynthetic bacteria. In Advances in Nitrogen Fixation Research pp. 181-187. Edited by C. Veeger \& W. E. Newton. The Hague: M. Nijhoff/W. Junk.

Trinchant, J. C. \& Rigaud, J. (1987). Acetylene reduction by bacteroids isolated from stem nodules of Sesbania rostrata. Specific role of lactate as an energy-yielding substrate. Journal of General Microbiology 133, 37-43. 